\title{
Correction to: Planted forests and natural regeneration in forest transitions: patterns and implications from the U.S. South
}

\author{
John Schelhas ${ }^{1}$ • Thomas J. Brandeis ${ }^{1}$ • Thomas K. Rudel ${ }^{2}$
}

Published online: 5 February 2021

(C) Springer-Verlag GmbH Germany, part of Springer Nature 2021

Correction to: Regional Environmental Change (2021) 21:8. https://doi.org/10.1007/s10113-020-01725-3

This article has an error that was introduced during the publishing process. In this paper, Figure 3 is mistakenly identical to Figure 2. The correct Figure 3 and its caption are provided here.

The original article has been corrected.

The online version of the original article can be found at https://doi.org/ 10.1007/s10113-020-01725-3

John Schelhas

John.schelhas@usda.gov

1 Southern Research Station, USDA Forest Service, 320 Green Street, Athens, GA 30602, USA

2 Departments of Human Ecology and Sociology, Rutgers University, New Brunswick, NJ, USA 


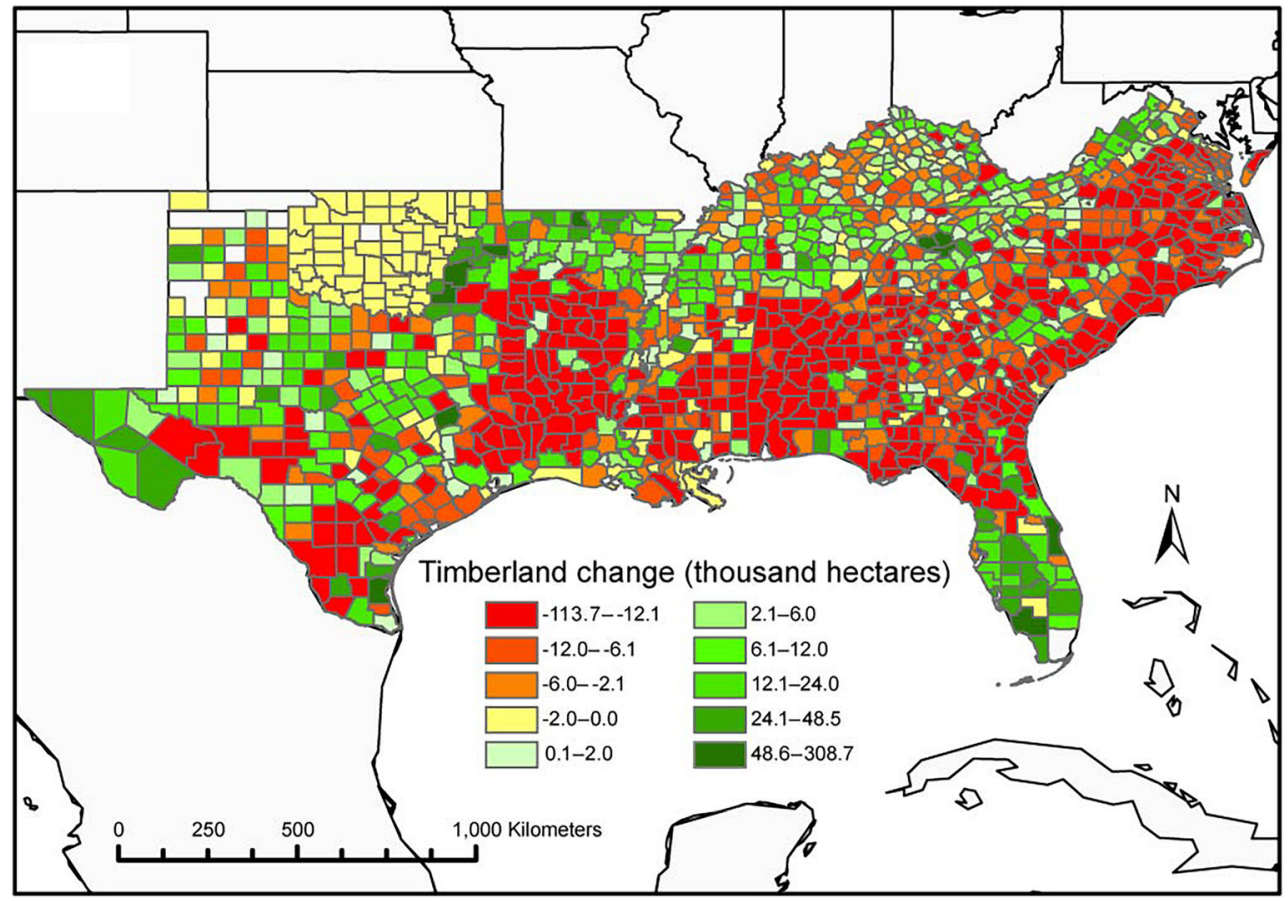

Fig. 3 County level change in naturally regenerated timberland in the southern United States, 1968 to 2016

Publisher's Note Springer Nature remains neutral with regard to jurisdictional claims in published maps and institutional affiliations. 